\title{
Políticas de expansão da educação superior no Brasil: a formação de professores a distância na UAB
}

\author{
Expansion of higher education policy in Brazil: distance teacher \\ training at $U A B$ \\ Políticas de expansión de la educación superior en Brasil: formación del \\ profesorado a distancia en la UAB \\ DENILDA CAETANO DE FARIA \\ MOISÉS GREGÓRIO DA SILVA \\ MARIA ZENEIDE CARNEIRO MAGALHÃES DE ALMEIDA
}

Resumo: O objetivo do estudo é compreender a formação docente a distância no contexto de expansão e interiorização da educação superior. São trazidas reflexões sobre o processo de implementação das políticas de formação de professores a distância na educação superior e suas implicações, mais especificamente na Universidade Federal do Tocantins (UFT). A metodologia adotada recorre a fontes bibliográficas e documentais e a entrevistas com os coordenadores de cursos da UFT que atuam em dois polos da Universidade Aberta do Brasil (UAB) situados no interior do estado do Tocantins. Os resultados evidenciam que houve um aumento significativo de oferta de cursos de licenciaturas a distância no estado; contudo, muitos desafios precisam ser superados no sentido de ampliar o acesso e garantir a qualidade na formação docente.

Palavras-chave: Formação docente; Educação a Distância; UAB.

Abstract: The aim of the study is to understand the distance teacher training in the context of expansion and internalization of higher education. We bring reflections on the process of implementation of the distance teacher training policies in higher education and its implications, specifically in the Federal University of Tocantins (UFT). The methodology uses bibliographical and documentary sources, and interviews with UFT courses coordinators who work in two poles of the Open University of Brazil (UAB) located in the State of Tocantins. The results show that there was a significant increase in the supply of teacher training in distance courses in the state. However, many challenges must be overcome in order to expand access and ensure quality in teacher training.

Keywords: Teacher training; distance education; UAB.

Resumen: El objetivo del estudio es comprender la formación docente a distancia en el contexto de la expansión e interiorización de la educación superior. Reflexiones son presentadas sobre el proceso de implementación de las políticas de formación de profesores a distancia en la educación superior y sus implicaciones, más específicamente en la Universidad Federal de Tocantins (UFT). La metodología adoptada utiliza fuentes bibliográficas y documentales y entrevistas con los coordinadores de cursos de la UFT que actúan en dos polos de la Universidad Abierta de Brasil (UAB) ubicados en el interior del estado de 
Tocantins. Los resultados evidencian que hubo un aumento significativo de la oferta de cursos de profesorado a distancia en el estado; sin embargo, muchos desafíos necesitan ser superados con el fin de ampliar el acceso y asegurar la calidad en la formación docente.

Palabras clave: Formación del profesorado, educación a distancia, UAB.

\section{INTRODUÇÃO}

Este estudo tem como objeto de estudo as políticas de expansão da Educação Superior no Brasil, mais especificamente, a formação de professores a distância, com a finalidade de compreender as ações e intervenções políticas destinadas à formação docente a distância com o aporte das Tecnologias de Informação e Comunicação (TIC) por meio da Universidade Aberta do Brasil (UAB) no contexto de expansão e interiorização da educação superior,

Nas últimas décadas, a educação a distância com a incorporação das TIC vem se tornando uma intervenção política de expansão do acesso à Educação Superior, ganhando força e ampliando seu campo de atuação com a criação da UAB, em 2006.

O ensino a distância como modalidade educacional formal no Brasil foi estabelecido com a promulgação da atual Lei de Diretrizes e Bases da Educação Nacional - LDB (Lei n. 9394/96). Entretanto, somente em 2006 foi instituída a UAB, com a finalidade sistematizar ações, programas, projetos e atividades voltados para a expansão e interiorização do ensino superior.

Atualmente, na Educação Superior, a EaD com o aporte das TIC vem ampliando a oferta de vagas em diversas regiões brasileiras como forma de atender às necessidades de formação dos profissionais que atuam na educação básica. Diante desses apontamentos iniciais, o presente artigo tem como objetivo compreender a formação docente a distância no contexto de expansão e interiorização da educação superior e suas implicações, e, mais especificamente, na Universidade Federal do Tocantins (UFT).

\section{POLÍTICAS DE EXPANSÃO DA EDUCAÇÃO SUPERIOR E A EAD NA FORMAÇÃO DE PROFESSORES}

No governo Lula e no governo de Dilma Rousseff, o Programa Universidade para Todos (PROUNI), o Programa de Apoio a Planos de Reestruturação e Expansão das Universidades Federais (REUNI) e a Educação a Distância são políticas voltadas para a expansão da Educação Superior. 
Para Faria (2014), essas intervenções políticas são criadas como forma de propulsionar o desenvolvimento mediante ensino e pesquisas adaptadas a atender à economia e à sociedade em razão da competitividade ocasionada pela globalização. Em decorrência disso, ampliou-se a demanda por conhecimento e informações. Com a finalidade de atender a essa demanda, as políticas educacionais, na EaD são implementadas no ensino superior articuladas com o Ensino Médio com vistas a atender a necessidades de profissionalização do mercado.

A oferta de vagas na EaD cresceu exponencialmente, de em torno de mais de seis mil, em 2000, para 1,7 milhão, em 2010, quantidade quase igual ao número de concluintes do ensino médio nesse ano, que foi de 1,8 milhão (MANCEBO; VALE; MARTINS, 2015).

Para as autoras, a justificativa para a acelerada expansão da EaD vem da crença da TIC como solução milagrosa para os mais diversos problemas, em especial a partir da segunda metade do século XX, com o uso cada vez maior da técnica como dispositivo neutro. "A hipertrofia da dimensão técnica, em diversos campos, inclusive no educacional, traduz uma crença no determinismo tecnológico, apresentando a tecnologia descontextualizada do meio social que a circunda" (Idem, p. 44).

Ao longo do tempo, a história da $\mathrm{EaD}$ vem sofrendo grandes transformações e inovações, desde os cursos por correspondência, passando pela incorporação de novas mídias, como a televisão, o rádio e o vídeo, até a atualidade, com o surgimento das redes de computadores sustentadas pela internet. Atualmente, denominada educação on line, a EaD vem gradativamente consolidando-se como política de expansão do acesso à Educação Superior, com prioridade para a formação de professores.

Ao se considerar a formação de professores a distância com o uso das TIC, faz-se necessário analisar os marcos regulatórios em textos legais que tratam do assunto. Com a promulgação da Lei 9394/96, Lei de Diretrizes e Bases da Educação Nacional (LDB), a EaD passou a ser estabelecida como modalidade educacional no país. De acordo com o artigo 80, “o poder público incentivará o desenvolvimento e a veiculação de programas de ensino a distância, em todos os níveis e modalidades de ensino, e de educação continuada" (BRASIL, 1996).

O Decreto n. 2.494, de 10 de fevereiro de 1998, complementa o referido artigo da LDB, ao preconizar no artigo $1^{\circ}$. que a educação a distância "É uma forma de ensino que possibilita a autoaprendizagem, com a mediação de recursos didáticos sistematicamente organizados, apresentados em diferentes suportes de informação, utilizados isoladamente ou combinados, e veiculados pelos diversos meios de comunicação" (BRASIL, 1998). 
O Decreto n. 5.622, de 19 de dezembro de 2005, ao regulamentar o artigo 80 da LDB 9.394/96, caracteriza a educação a distância como modalidade educacional na qual a mediação didático-pedagógica nos processos de ensino e aprendizagem ocorre com a utilização de meios e tecnologias de informação e comunicação, com estudantes e professores desenvolvendo atividades educativas em lugares ou tempos diversos. Estabelece, também a obrigatoriedade de momentos presenciais que contemplem as avaliações de estudantes, estágios, defesas de trabalhos e atividades laboratoriais.

Nesse sentido, confere as instituições que detêm prerrogativa de autonomia universitária credenciadas para oferta de Educação Superior a distância poderão criar, organizar e extinguir cursos ou programas de Educação Superior nessa modalidade, mas estabelece que os cursos ou programas criados sejam ofertados nos limites da abrangência definida no ato de credenciamento da instituição. Do mesmo modo, o Decreto confere ao Ministério da Educação a prerrogativa de promover os atos de credenciamento de instituições para oferta de cursos e programas a distância para Educação Superior (BRASIL, 2005).

A EaD, como intervenção política direcionada para a formação docente, vem gradativamente ampliando seu campo de atuação para atender às demandas de qualificação profissional, sobretudo de professores para a Educação Básica. $\mathrm{Na}$ LDB 9394/96, a formação docente é explicitada no artigo 62 da seguinte forma:

A formação de docentes para atuar na educação básica far-se-á em nível superior, em curso de licenciatura, de graduação plena, em universidades e instituto superiores de educação, admitida, como formação mínima para o exercício do magistério na educação infantil e nas quatro primeiras séries do ensino fundamental, a oferecida em nível médio na modalidade Normal (BRASIL, 1996).

Brzezinski (2014), em sua obra intitulada "LDB/1996 contemporânea: contradições, tensões, compromissos", elucida que a Lei 12.056/2009 redimensionou o artigo $62 \mathrm{da} \mathrm{LDB} / 1996 \mathrm{com}$ o acréscimo dos seguintes parágrafos:

$\int 1^{\circ}$ A União, o Distrito Federal, os Estados e os Municípios, em regime de colaboração, deverão promover a formação inicial, a continuada e a capacitação dos profissionais de magistério. [...] $\mathbb{2} 2^{\circ}$ A formação continuada e a capacitação dos profissionais de magistério poderão utilizar recursos e tecnologias de educação a distância. [...] $₫ 3^{\circ} \mathrm{A}$ formação inicial de profissionais de magistério dará preferência ao ensino presencial, subsidiariamente fazendo uso de recursos e tecnologias de educação a distância (BRASIL, 2009 apud BRZEZINSKI, 2014, p. 132). 
De acordo com Brzezinski (2014), a Associação Nacional pela Formação dos Profissionais da Educação (ANFOPE) considera que a formação inicial seja realizada apenas em cursos presenciais, conforme aprovado pela Conferência Nacional de Educação (CONAE) em 2010.

O documento da CONAE 2010, importante referência para a formulação das políticas educacionais, propõe que a formação inicial pode ser ofertada, de forma excepcional na $\mathrm{EaD}$, em locais onde não existam cursos presenciais, mas sob rígida regulamentação, acompanhamento e avaliação, conforme o texto que descreve:

\begin{abstract}
A formação inicial deverá se dar de forma presencial, inclusive aquelas destinadas aos/às professores/as leigos/as que atuam nos anos finais do ensino fundamental e no ensino médio, como aos/às professores/as de educação infantil e anos iniciais do ensino fundamental em exercício, possuidores/as de formação em nível médio. Assim, a formação inicial pode, de forma excepcional, ocorrer na modalidade de $\mathrm{EaD}$ para os/as profissionais da educação em exercício, onde não existam cursos presenciais, cuja oferta deve ser desenvolvida sob rígida regulamentação, acompanhamento e avaliação (BRASIL, 2010, p. 83).
\end{abstract}

Apesar de o documento destacar a EaD como alternativa para a formação dos profissionais da educação em exercício, faz uma análise negativa quanto à oferta de cursos nessa modalidade ao pontuar a existência de vários cursos de EaD, em instituições que os ofertam em diversos polos localizados tanto no interior dos Estados como nas capitais, devido maioria deles serem oferecidos sem o devido acompanhamento pedagógico, sem aprovação do MEC e sem compromisso com a formação de qualidade dos estudantes, visando apenas ao lucro das instituições e à distribuição de diplomas de forma aligeirada, além de mencionar que:

A articulação entre o MEC e os sistemas de ensino, envolvendo as universidades no contexto da implantação de um sistema nacional de educação, deve visar às políticas públicas de ampliação e interiorização da oferta do ensino superior gratuito e de qualidade, priorizando o ensino presencial e fazendo o acompanhamento dos cursos de $\mathrm{EaD}$, de maneira que estes, quando forem necessários, sejam implantados com qualidade social (BRASIL, 2010b, p.84).

O documento de referência da CONAE de 2014 propõe que as políticas e programas direcionados à Educação Superior devem:

Promover a ampliação e democratização do acesso a esse nível educacional, destacando-se a garantia de matrícula à população de 18 a 24 anos em instituições de ensino superior, de modo a ampliar (atingir mais de 30\% de taxa líquida) e universalizar o acesso a esse nível de ensino (atingir mais de 50\% de taxa líquida). 
A expansão e democratização da Educação Básica e superior deverão superar as assimetrias e desigualdades regionais que historicamente têm marcado os processos expansionistas, sobretudo por meio de políticas de interiorização e de educação do campo (BRASIL, 2014b).

Dourado e Santos (2011), ao fazerem uma avaliação do Plano Nacional de Educação - PNE (2001-2010), apontando para a necessidade de melhoria do projeto de lei n. 8.035 (PNE 2011-2020), consideram que as metas propostas para a $\mathrm{EaD}$, na sua maioria, atingiram índices expressivos no que se refere à expansão da Educação Superior da modalidade, à construção de marco regulatório, ao credenciamento das instituições e à criação e autorização de cursos. Entretanto, como o PNE "não era o balizador das ações desencadeadas, não foram alcançadas as metas fundamentais da expansão com qualidade, especialmente as que previam a articulação com os sistemas e as instituições de ensino, como o acompanhamento e a avaliação" (p. 187).

Recentemente, em 25 de junho de 2014, a Lei n. 13.005, aprovou o novo PNE. A meta 12 da referida lei estabelece a ampliação de vagas na Educação Superior e aponta como uma das estratégias, no item 12.4, o fomento para que a oferta seja pública e gratuita, dê-se "Prioritariamente para a formação de professores e professoras para a Educação Básica, sobretudo nas áreas de ciências e matemática, bem como para atender ao deficit de profissionais em áreas específicas" (BRASIL, 2014).

Diante da necessidade de formação inicial e continuada de profissionais de magistério para a Educação Básica, as instituições de ensino superior (IES) buscam na EaD ampliar seu campo de atuação. Nessa perspectiva, o Ministério de Educação (MEC) vem implementando várias ações e programas direcionados à melhoria da Educação Básica, dentre eles o desenvolvimento do Pró-Licenciatura e, posteriormente, o Programa Universidade Aberta do Brasil, com a finalidade de ofertar cursos de graduação (licenciaturas) a distância para a formação e qualificação do professor que atua em sala de aula das instituições públicas.

Os editais publicados para o programa de formação de professores durante o ano de 2003, dentre eles o do Programa de Incentivo à Formação Continuada de Professores do Ensino Médio (PROINFEN), foram utilizados como base para o desenvolvimento de um edital ampliado para os cursos de licenciatura no ano de 2004. Nesse período, foi lançado o primeiro edital destinado aos cursos de graduação em instituições interessadas em ofertar graduação a distância nas áreas de Matemática, Física, Química, Biologia e Pedagogia (CARVALHO; PIMENTA, 2010). 
Em 2005, foi implementado pelo MEC o Pró-Licenciatura (Fase 2). Nessa fase, as instituições interessadas em ofertar cursos de licenciatura a distância tiveram de participar de um processo seletivo. De acordo com o artigo $2^{\circ}$. da Resolução CD/FNDE n. 34, de 9 de agosto de 2005, as IES deveriam:

\footnotetext{
Ofertar cursos de licenciatura, com duração igual ou maior que a mínima exigida para os cursos presenciais, na modalidade de educação a distância para formação inicial de professores em exercício nas redes públicas nos anos/séries finais do Ensino Fundamental e/ou no Ensino Médio, sem licenciatura na disciplina em que estejam exercendo a docência (BRASIL, 2005).
}

Carvalho e Pimenta (2010) ressaltam que ao documento de seleção foram incorporados dois anexos relevantes direcionados às questões de elegibilidade e organização das IES interessadas. Para as autoras, com as diretrizes conceituais e metodológicas sobre o perfil dos cursos de licenciatura a distância, estabeleceuse um padrão determinado para os projetos políticos-pedagógicos das propostas enviadas ao MEC, por razão de as instituições estarem cientes de que deveriam seguir, além dos critérios de elegilibidade e previsão orçamentária dos cursos, as orientações relacionados ao perfil político destes.

Em dezembro de 2005, foi publicado um edital, denominado posteriormente de Edital UAB 1, seis meses antes da criação oficial do sistema UAB. O Pró-Licenciatura foi então substituído por nova proposta, a UAB, com mudanças e inovações no propósito governamental de Educação a Distância (CARVALHO; PIMENTA, 2010).

Barreto (2010) afirma que a recontextualização educacional focada na formação de professores teve como primeiro marco a Secretaria de Educação Continuada (SEED), criada em 1995, com a finalidade de coordenação das ações inerentes às TIC e tendo como meta "levar para a escola pública toda a contribuição que os métodos, técnicas e tecnologias de educação a distância podem prestar à construção de um novo paradigma para a educação brasileira" (p. 1304). Para a autora, as linhas de ação da SEED fundamentam-se na existência de um sistema tecnológico "cada vez mais barato, acessível e de manuseio mais simples" capaz de:

Trazer para a escola um enorme potencial didático-pedagógico; ampliar oportunidades onde os recursos são escassos; familiarizar o cidadão com a tecnologia que está em seu cotidiano; dar respostas flexíveis e personalizadas para pessoas que exigem diversidade maior de tipos de educação, informação e treinamento; oferecer meios de atualizar rapidamente o conhecimento; estender os espaços educacionais; e motivar os profissionais e alunos para aprenderem continuamente, em qualquer estágio de suas vidas (BARRETO, 2010, p. 1305). 
No entendimento da autora, embora o núcleo da EaD na SEED mencione a escola "como espaço privilegiado da atividade educacional", promove, por outro lado, a "fetichização máxima" ao propor ações voltadas ao sistema tecnológico, colocando as tecnologias no lugar dos sujeitos.

Para Leal (2013), a SEED/MEC foi reestruturada para potencializar sua atuação por meio de recursos para capacitar: gestores de escolas públicas e de secretarias estaduais e municipais de educação, alunos do ensino fundamental e médio e, com destaque, professores (na formação inicial e continuada), dando início a um trabalho colaborativo e fazendo avançar a integração entre parceiros e programas. Dentre estes, destacam-se os programas voltados à formação de professores, "Além da TV Escola, o Programa Nacional de Informática na Educação (ProInfo), o Programa de Formação dos Professores em Exercício (Proformação) e o Programa de Apoio à Pesquisa em Educação a Distância (PAPED)" (p. 75),. Para o autor, o governo Lula justificou a reestruturação da SEED/MEC

Com um discurso governamental de que a educação em todos os níveis é uma das prioridades de seu governo. $\mathrm{O}$ discurso da sociedade democrática pode ser alcançado por meio da $\mathrm{EaD}$, modalidade de ensino que tem as condições necessárias para atender às demandas educacionais que se apresentam, bem como maiores possibilidades de concretizar mudanças no panorama educacional agora, por meio da UAB (Idem, p. 76).

Além da criação, em 1995, da Secretaria de Educação Continuada (SEED), foi implantada, em dezembro de 1999, a Universidade Virtual Pública do Brasil (UniRede).

Tratou-se de um consórcio interuniversitário criado com o propósito “dar início a uma luta por uma política de Estado visando à democratização do acesso ao ensino superior público, gratuito e de qualidade e o processo colaborativo na produção de materiais didáticos e na oferta nacional de cursos de graduação e pós-graduação" (UNIREDE, 2013).

Barreto (2010) aponta fragilidade na estrutura da UniRede, por esta ser dependente do apoio da Comissão de Educação/Frente Parlamentar de Educação a Distância da Câmara Federal, dos Ministérios (MEC e MCT), de órgãos como a Financiadora de Estudos e Projetos (FINEP) e, sobretudo, do Conselho Nacional de Desenvolvimento Científico e Tecnológico, na concessão de bolsas para apoiar o desenvolvimento das ações nos polos.

Ao analisar o estudo realizado pelo Grupo de Trabalho Interministerial instituído pelo Decreto Presidencial de 20 de outubro de 2003, encarregado de analisar a situação das universidades e apresentar plano de reforma, Barreto (2010) observa que o diagnóstico e a proposta do GT apontam para a revisão do

858 - RBPAE - v. 32, n. 3, p. 851 - 870 set./dez. 2016 
marco regulatório do ensino superior, em pleno acordo com as determinações dos organismos internacionais para a periferia do capitalismo. Para a autora, o documento tem como premissa o "redesenho" das universidades com ênfase na EaD. Dessa forma, atende às diferentes dimensões do modelo neoliberal com a finalidade de:

(a) Diminuir significativamente o número de professores e duplicar o número de alunos; (b) baratear drasticamente os custos das universidades; (c) deslocar o foco da formação para o seu produto, desde que sejam utilizados testes adequados para aferir as competências-alvo, traduzidas nos "materiais educacionais que garantam larga utilização", disponíveis em polos descentralizados. (p. 1305)

Nesse contexto, a situação das universidades se torna complexa. Com a redução de recursos para as universidades públicas e com a aposta na "substituição tecnológica", elas têm de adequar-se aos limites impostos pelo governo e expandir a oferta de vagas por meio da UAB, com o apoio das TIC.

\section{A UAB COMO POLÍTICA DE EXPANSÃO DA EDUCAÇÃO SUPERIOR}

O desenho da UAB foi construído no contexto do Fórum das Estatais pela Educação, com foco nas Políticas e na Gestão da Educação Superior. Considerouse relevante a experiência da UniRede e se decidiu ampliar suas ações com o apoio de empresas não estatais e de instituições de Educação Superior públicas e privadas. No processo de implementação da UAB, destaca-se a comparação explícita: "a estrutura básica da UAB e dos Consórcios deve se assemelhar mais a uma fábrica, enfatizando a alta produção de cursos" (BARRETO, 2010, p. 39). $\mathrm{Na}$ concepção da autora, o sistema vem crescendo gradativamente com polos nos diferentes Estados, "em perspectiva eminentemente técnica" (Ibidem).

Assim, o sistema UAB foi instituído oficialmente pelo Decreto n. 5.800, de 8 de junho de 2006. Surgiu com o intuito de expandir e interiorizar a oferta de cursos e programas de Educação Superior no país mediante a oferta de cursos e programas a distância por instituições públicas de ensino superior, em articulação com polos de apoio presencial. De acordo com art. $1^{\circ}$. do referido decreto, as finalidades do Sistema UAB são:

I - oferecer, prioritariamente, cursos de licenciatura e de formação inicial e continuada de professores da educação básica; [...] II - oferecer cursos superiores para capacitação de dirigentes, gestores e trabalhadores em educação básica dos Estados, do Distrito Federal e dos Municípios; [...] III - oferecer cursos superiores nas diferentes áreas do conhecimento; [...] IV - ampliar o acesso à educação 
superior pública; [... ] V - reduzir as desigualdades de oferta de ensino superior entre as diferentes regiões do País; [...] VI - estabelecer amplo sistema nacional de educação superior a distância; e [...] VII - fomentar o desenvolvimento institucional para a modalidade de educação a distância, bem como a pesquisa em metodologias inovadoras (BRASIL, 2006. Art. $1^{\circ}$ ).

De acordo com informações no site da $\mathrm{UAB}^{1}$, o Sistema da Universidade Aberta do Brasil funciona como um articulador entre as instituições de ensino e os governos estaduais e municipais. Tal articulação se sustenta em cinco eixos fundamentais: I - Expansão pública da Educação Superior, considerando os processos de democratização e acesso; II - Aperfeiçoamento dos processos de gestão das instituições de ensino superior, possibilitando sua expansão em consonância com as propostas educacionais dos estados e municípios; III - Avaliação da Educação Superior a distância tendo por base os processos de flexibilização e regulação implantados pelo MEC; IV - Estímulo à investigação em Educação Superior a distância no País; V - Financiamento dos processos de implantação, execução e formação de recursos humanos em Educação Superior a distância.

Costa e Pimentel (2009) defendem que, para o Brasil, país continental com imensas desigualdades sociais e econômicas, o apoio da EaD no processo de emancipação pela Educação é essencial. Ainda que essa modalidade de ensino não possa abranger tudo, seu uso se constitui em importante ferramenta de ação educacional, desde que as soluções de qualidade propostas coloquem o aluno no centro do processo pedagógico. As autoras analisam que a UAB tem o grande desafio "de levar a Educação Superior de qualidade de nossas instituições públicas a todos os espaços, mesmo os mais remotos e afastados dos grandes centros, ajudando a promover a emancipação social e econômica de nosso povo através da educação" (p. 89).

Ao analisar a regulação da formação de professores a distância por meio da UAB, Barreto (2010) chama atenção para o Decreto n. 6.755, de 2009, que disciplina a atuação da Coordenação de Aperfeiçoamento de Pessoal de Nível Superior (CAPES) no fomento a programas de formação inicial e continuada. A autora avalia que ele é constituído por um discurso híbrido que justapõe formulações inscritas em matrizes diversas, por isso demanda uma análise mais aprofundada de seus pressupostos e dos modos pelos quais suas contradições poderiam ser resolvidas. Na concepção da autora, é o caso de "ampliar o número de docentes atuantes na Educação Básica pública que tenham sido licenciados

1 Disponível em: <htpp://www.capes.gov.br/uab>. Acesso em: 11de dez. de 2014. 
em instituições públicas de ensino superior, preferencialmente na modalidade presencial, e de remeter ao acervo de cursos e tecnologias educacionais do MEC" (p. 39-40).

O documento reforça a intenção de promover mudanças nos diferentes cursos de formação de professores a partir da experiência da formação a distância, o que pode ser sugestivo de uma intervenção que fere a autonomia universitária. Barreto (2010) analisa que o traço mais comum nos documentos que tratam da regulação da política de formação de professores a distância é a premissa da incorporação das TIC como substituição pedagógica. Além disso, observa-se um conjunto de políticas em andamento que tem como característica projetos "centrados na distribuição de laptops como meio de elevar a qualidade da educação pública, seja para os professores, seja para os alunos, como no projeto Um Computador por Aluno (UCA), ação conjunta do Ministério da Educação e da Casa Civil para a 'inclusão digital' (Idem, p. 40).

Dessa forma, as TIC pensadas para a formação de professores a distância acabam contribuindo para uma cadeia de simplificações em torno da "flexibilização estratégica", as quais possibilitam colocar em questão a modalidade em função do "modus operandi", (Idem, p. 41). No entendimento da autora, a política nacional de formação de professores a distância requer a superação do modelo de substituição tecnológico, ora hegemônico, bem como uma análise dos processos de ensinar e aprender, considerando que,

\footnotetext{
No decantado "novo paradigma" educacional, reiterado nos discursos do Banco Mundial e da Seed, é operada a quebra da unidade (ensino-aprendizagem) que tem sustentado os mais diversos estudos acerca das práticas educativas, na medida em que deixa de contemplar o primeiro elemento do par para a concentração no segundo, concebido como "auto-aprendizagem" decorrente do acesso à informação ou ao conhecimento, como expansão de "oportunidades" e, até, de "acesso à aprendizagem", como se esta não se referisse a um processo interno (p. 42).
}

Como se pode perceber, a regulação da formação de professores a distância por meio da UAB tem sido complexa e contraditória, por agregar novos elementos e condições de trabalho diferenciadas, o que torna a docência on line com o uso das TIC mais desafiadora.

\section{FORMAÇÃO DE PROFESSORES A DISTÂNCIA NA UFT}

A UFT, desde o primeiro ano de sua implantação, em 2003, vem participando e promovendo discussões para a implementação da educação a distância por meio de fóruns, seminários e teleconferências. Durante o ano de 
2005, a EaD começou a ser implementada na UFT em Arraias, quando duas professoras desse campus desenvolveram uma proposta de curso nessa modalidade e se disponibilizaram a iniciar a implementação do projeto na instituição.

Em 2006, a UFT iniciou uma parceria com a Universidade de Brasília (UnB), quando participou do primeiro edital ${ }^{2}$ de chamada para oferta do curso de licenciatura em Biologia a distância. Posteriormente, a universidade participou de todos os editais de chamada pública para ofertas de cursos do sistema UAB. Além desses, a UFT oferta outros cursos na plataforma Moodle da instituição.

A implementação do curso de licenciatura em Biologia a distância da UFT foi regulamentada por meio da Resolução do Conselho Universitário (CONSUNI) n. 06/2005, de 13 de outubro de 2005 (UNIVERSIDADE FEDERAL DO TOCANTINS, 2005). De acordo com Nass (2012), o processo de implantação da EaD na UNIVERSIDADE FEDERAL DO TOCANTINS teve início com a adesão ao Consórcio Setentrional, liderado pela UnB, para a oferta da licenciatura em Biologia no âmbito do programa Pró-Licenciatura.

O início dos cursos de licenciatura em Química e Física na UFT ocorreu em 2010. Eles foram implementados na instituição com base nos Projetos Pedagógicos do Curso (PPC) dessas licenciaturas da Universidade Federal do Rio Grande do Norte (UFRN). Nass (2012) observa que "praticamente nenhuma experiência do curso de licenciatura em Biologia foi aproveitada para os cursos de Física e Química” (p. 92).

O curso de licenciatura em Química surgiu na UFT na mesma perspectiva do curso de Física, ou seja, da necessidade de formação de professores no campo, visto que, segundo dados da Secretaria Estadual de Educação e Cultura, as áreas de Física e Química eram as de maior carência do Estado do Tocantins (UNIVERSIDADE FEDERAL DO TOCANTINS, 2009).

No Projeto Pedagógico Institucional (PPI) a educação a distância é considerada um dos programas estratégicos da instituição (UNIVERSIDADE FEDERAL DO TOCANTINS, 2007). O documento destaca como fator primordial a realização de uma discussão mais aprofundada sobre a $\mathrm{EaD}$ nos órgãos colegiados com o intuito de fortalecer e ampliar a estrutura da instituição, além propor novas políticas para essa modalidade educativa. De acordo com o documento, as diretrizes para as políticas de $\mathrm{EaD}$ são:

I Propor e implementar a política de educação a distância, tendo como referência a qualidade acadêmica, a articulação com as demais políticas educacionais da UFT, a sua necessária ação integradora entre as várias áreas do conhecimento e o seu papel social. [...] II.Implementar um sistema de avaliação contínua dos cursos a

2 Disponível em: <http://www.uab.capes.gov.br/images/stories/downloads/editais/editaluab1. pdf $>$. Acesso em: 15 de fev. de 2016.

862 - RBPAE - v. 32, n. 3, p. 851 - 870 set./dez. 2016 
distância. [...] III. Formar grupos de estudos e aprofundamento de temas relativos à inserção das tecnologias nos cursos de graduação. [...] IV. Promover a articulação do ensino, pesquisa e extensão como princípio norteador dos cursos de graduação a distância (p.5).

$\mathrm{Na}$ UFT, atualmente, muitas ações e projetos direcionados para a formação de professores estão vinculados ao sistema UAB, dentre eles a oferta de cursos de licenciaturas em Biologia, Química, Física e Matemática. Embora os cursos de licenciatura em Química e Física tenham sido iniciados em 2010, após o início do curso de licenciatura em Biologia (que teve sua primeira oferta em 2006), a experiência deste não foi utilizada no processo de implementação. Conforme mencionado, os fundamentos das propostas pedagógicas dos cursos da UFRN foram as referências. Para Nass (2012), a experiência da UFT também tem características particulares reprodutíveis em outros cursos ofertados pela UAB, "como o colegiado plenamente participativo e os momentos presenciais com cada um dos professores de disciplina em todos os polos" (p. 165).

Assim, desde 2003, a gestão da EaD na UFT e alguns professores envolvidos com a educação mediada por tecnologias vêm desenvolvendo ações voltadas para a implementação e institucionalização dessa modalidade de ensino. Nessa direção, em 2014, com o intuito de expandir seu campo de atuação, a instituição passou a ofertar o curso de licenciatura em Matemática. Esse curso também surgiu diante da demanda de formação de professores na área, e sua implementação, à semelhança dos cursos de licenciatura em Química e Física, teve como base o PPC de Matemática na modalidade EaD da UFRN. Essa universidade "[...] compartilhou com a UFT a matriz do material didático do curso, ficando sob a responsabilidade dessa instituição a adequação do material à realidade local, a reprodução do mesmo e a oferta do curso" (UNIVERSIDADE FEDERAL DO TOCANTINS, 2013, p. 37).

\section{A IMPLANTAÇÃO DA EAD E DOS CURSOS DE LICENCIATURAS A DISTÂNCIA NA CONCEPÇÃO DOS COORDENADORES}

Na UFT, o processo de implantação da EaD se iniciou em 2004, com a constituição de um Grupo de Trabalho (GT) formado por professores, técnicoadministrativos e estudantes, liderado pela gestão da reitoria, com a finalidade de propor e discutir ações voltadas para a implementação dessa modalidade de 
ensino na instituição. Na concepção de um coordenador de curso, o GT encontrou grande resistência por parte dos professores ao desenvolvimento de suas ações; como relata: um coordenador de curso:

Houve grande rejeição na época na UFT pela implantação. Na verdade, o curso de Biologia seria um curso-piloto, um modelo, que a partir dele pudéssemos discutir outros cursos. A rejeição se deu por ser algo novo. Eu lembro que naquela reunião do CONSEPE, instância em que foi aprovado o curso de Biologia, a discussão era: como que você vai ensinar Biologia a distância? Como é que você vai propor as ferramentas para o futuro professor trabalhar na sala de aula? Isso foi uma discussão tensa, muita gente não aceitava, por acreditarem que com a implementação da EaD estaríamos nadando contra a corrente (coordenador de curso 1).

Apesar das controvérsias e resistências quanto ao processo de implantação da EaD na UFT, as discussões avançaram no âmbito da universidade, com a adesão desta ao Consórcio Setentrional, organizado pela UnB para a oferta do curso de Biologia. Com isso, em 2007, a primeira turma desse curso ingressou na UFT via EaD e, entre o período de 2010 e 2014, os cursos de Física, Química e Matemática foram implementados na instituição por meio da UAB. O coordenador de curso entrevistado relata:

Então, falando de EaD na UFT, pode-se perceber o tanto que ela evoluiu desde a sua implantação. Claro, a gente tinha só o curso de Biologia com um formato que nem se pode dizer que era um curso a distância, porque o formato do curso de Biologia iniciou naquele Consórcio Setentrional, que era diferenciado do que hoje a gente tem, o curso da UAB (coordenador de curso 1).

A implementação dos cursos de licenciatura ofertados pelo sistema UAB nos dois polos UAB encontra-se em processo de consolidação, como afirma a coordenadora:

\footnotetext{
Nós temos muito que avançar, por exemplo, no curso de Matemática, temos muitas lacunas em se tratando de curso a distância. O que a gente precisa enquanto curso a distância? Precisamos de um laboratório, nós já temos agora, conseguimos um laboratório multidisciplinar de tecnologia. Esse laboratório dá as condições pra você fazer, por exemplo, uma videoaula. Entretanto, precisamos de um treinamento para utilizá-lo (coordenador de curso 2).
}

Uma preocupação recorrente percebida na fala dos coordenadores de curso refere-se ao material didático utilizado, por não ser elaborado pelos professores da UFT e, sim, pelos docentes que atuam em uma universidade da região Nordeste, como destaca outro coordenador de curso: 
Então, porque lá na UFRN eles produzem o material didático, lá eles têm laboratório de produção de material didático. A gente já foi pra lá umas duas vezes visitar eles. Eles possuem uma equipe que elabora, corrige, imprime, distribui o material. Lá a produção é deles. [...] Então, quando o material didático foi adotado pela UFT, nós começamos a utilizá-lo. [...] O problema da região Nordeste é a água. E nós estamos na região Norte e o nosso problema não é água. [...] A realidade de lá é uma, a realidade daqui é outra. Então, nós adaptamos esse material didático à realidade local (coordenador de curso 3).

O coordenador de curso que atua em outro polo da UAB diz que os professores ainda estão utilizando material didático de outras universidades por não terem condições de produzir o material da UFT. Ele acrescenta que

\begin{abstract}
Esse material didático é postado no AVA. Sempre sugerimos aos professores que também seja inserido no ambiente de aprendizagem uma aula em vídeo, que o professor pode pesquisar no Youtube. [...] Só que os alunos reclamam que fica um distanciamento entre o professor que é responsável pela disciplina. Eles pensam que se o professor da disciplina criasse seu próprio vídeo, haveria uma maior aproximação entre professor e aluno, além de facilitar o entendimento deles (coordenador de curso 2).
\end{abstract}

Segundo o depoimento dos coordenadores, o acesso à internet em alguns municípios do interior do Estado Tocantins é limitado; com isso, os alunos em formação encontram dificuldades para realizar as atividades propostas pelo curso, o que fica claro na fala do coordenador de curso:

Outra coisa que temos no nosso contexto do Tocantins é que a internet oscila muito. Por exemplo, na cidade de Mateiros, nós temos um polo lá também, lá o sinal da internet não é bom. E aí eles ficam às vezes uma semana sem internet, duas semanas sem internet, isso acontece frequentemente em Mateiros, principalmente no período da chuva. Esse é o grande problema, vamos supor que ele não salvou o material, se ele não tiver internet, ele não consegue nem estudar (coordenador de curso 1).

Essa situação faz com que os professores adotem outras estratégias, como a impressão de apostilas e a produção de CD que contemple o material didático. Entretanto, atualmente essa estratégia se tornou inviável em razão de a $\mathrm{UAB}$ não disponibilizar verba para essa finalidade. Como declara o coordenador do curso:

Não, porque não existe verba para essa finalidade, não existe verba pra $C D$, não existe verba pra material impresso, não existe verba pra quase nada. Mas isso é um problema da UAB. Hoje ela entende que o curso a distância, ele tem que ser 
totalmente no AVA. Ele não pode ter esse suporte físico. [...] Penso que essas intervenções na política de $\mathrm{EaD}$ precisam ser redimensionadas. [...] Devido ao contexto dessas políticas, talvez a UAB está vendo a realidade brasileira de forma geral, e não local. Esse é o grande problema desses programas nacionais (coordenador de curso 3).

Apesar dos desafios encontrados, os coordenadores entrevistados foram quase unânimes em afirmar que a chegada dos cursos de licenciaturas à UFT por meio dos polos da UAB no Tocantins vem contribuindo para atender às demandas de formação de professores, sobretudo no interior, onde há grande carência de professores que atuem na Educação Básica, em especial nos cursos de Química, Física, Matemática e Biologia.

Portanto, verificamos que as políticas de formação profissional ofertadas por intermédio da $\mathrm{EaD}$ vêm crescendo gradativamente na UFT, embora muitos desafios ainda devam ser superados a fim de que essa intervenção possa ampliar o acesso ao ensino superior com qualidade na formação de professores. Nesse sentido, cabe retomar o entendimento de Mancebo, Vale e Martins (2015) sobre as relações entre as TIC e o EaD. Para as autoras,

Tratar as relações entre as TIC e o EaD como inevitáveis e desejáveis para um novo paradigma educacional, porque apresentam a potencialidade de solucionar os problemas atuais, é simplificar a questão, desconsiderando, entre outros aspectos, que essa solução foi imposta de modo vertical, sem levar em conta as condições de trabalho nas escolas, o duro cotidiano enfrentado por alunos e professores, a experiência que esses personagens acumularam ao longo da vida pessoal e coletivamente (p. 44).

\section{CONSIDERAÇÕES FINAIS}

A Educação a distância no Brasil tem desempenhado papel relevante no processo de expansão e interiorização do ensino superior como possibilidade de inclusão daqueles que a ele não tiveram oportunidades de acesso, embora muitos desafios ainda precisem ser superados, como abordado neste estudo.

Nesse cenário, de expansão das universidades públicas, a $\mathrm{EaD}$ vem gradativamente ampliando seu campo de atuação como forma de atender às demandas de qualificação profissional, em especial de professores para a Educação Básica. A ampliação da oferta de cursos de licenciatura a distância na UFT, sobretudo a partir da criação da UAB, revela esse processo.

Os cursos de licenciatura em Biologia, Química, Física e Matemática a distância surgiram com a finalidade de atender às demandas de formação de professores para atuar na Educação Básica, em contexto de expansão e interiorização da Educação Superior. Os três últimos cursos foram criados a partir 
de 2010 com base nos projetos pedagógicos da UFRN, sem aproveitamento da experiência do curso de licenciatura em Biologia a distância já implementado na UFT desde 2005.

Em síntese, considera-se importante a experiência de outras universidades para a implementação dos cursos de EaD, qualquer que seja o modelo escolhido por uma IES, especialmente na formação de professores. Contudo, a preocupação central deve ser com a construção de processos pedagógicos que propiciem, além da ampliação do acesso ao ensino superior, um nível de formação docente de qualidade com o aporte das TIC, sem desconsiderar as dimensões sociopolíticas, econômicas, culturais e históricas que permeiam o contexto de cada região brasileira.

\section{REFERÊNCIAS}

BARRETO, Raquel G. A formação de professores a distância como estratégia da expansão do ensino superior. Educação e Sociedade, Campinas, v. 31, n. 113, p. 1299-1318, out.-dez. 2010. Disponível em: <http://www.scielo.br/pdf/es/ v31n113/13.pdf>. Acesso em: 12 dez. 2015.

BARRETO, Raquel G. Configuração da política nacional de formação de professores a distância. Em Aberto, Brasília, v. 23, n. 84, p. 33-45, nov. 2010. Disponível em: <http://rbep.inep.gov.br/index.php/emaberto/article/ view/1789/1352>. Acesso em: 12 dez. 2015.

BRASIL. Conferência Nacional de Educação (CONAE). Documento de referência. Brasília: CONAE, 2014a.

Lei n. 13.005, de 25 de junho. Aprova o Plano Nacional de Educação. Portal da Legislação [do] Governo Federal. 2014b. Disponível em:

<http://www.planalto.gov.br/ccivil_03/_ato2011-2014/2014/lei/113005.htm>. Acesso em: 15 dez. 2015.

Documento Final, Conferência Nacional de Educação (CONAE). Brasília: CONAE, 2010.

Decreto n. 5.800, de 8 de junho. Dispõe sobre o Sistema Universidade Aberta do Brasil (UAB). Portal da Legislação [do] Governo Federal. 2006. Disponível em: <http://www.planalto.gov.br/ccivil_03/_ato2004-2006/2006/ decreto/d5800.htm>. Acesso em: 12 dez. 2014. 
Decreto n. 5.622, de 19 de dezembro. Regulamenta o art. 80 da Lei no 9.394/1996, que estabelece as diretrizes e bases da educação nacional.2005. Portal da Legislação [do] Governo Federal. Disponível em:

<http://www.planalto.gov.br/ccivil_03/_ato2004-2006/2005/decreto/d5622. htm>. Acesso em: 15 fev. 2016.

CD/FNDE. Resolução $\mathbf{n}^{\mathbf{0}}$ 34, de 06 de agosto. Dispõe sobre os critérios e os procedimentos para a apresentação, seleção e execução de projetos de cursos de licenciatura para professores em exercício nas redes públicas nos anos/séries finais do ensino fundamental e/ou médio, na EaD. Portal [do] Ministério da Educação. 2005. Disponível em:

$<$ http://portal.mec.gov.br/seb/arquivos/pdf/proli_res34.pdf>. Acesso em: 15 jan. 2016.

Decreto n. 2.494, de 10 de fevereiro. Regulamenta o Art. 80 da LDB (Lei 9.493/96) Portal da Legislação [do] Governo Federal. 1998, Disponível <http://www.planalto.gov.br/ccivil_03/decreto/D2494.htm>. Acesso em: 01 fev. 2016.

Lei n. 9.394, de 20 de dezembro. Estabelece as Diretrizes e Bases da Educação Nacional. Portal da Legislação [do] Governo Federal. 1996, Disponível em: <http://www.planalto.gov.br/ccivil_03/leis/L9394.htm>. Acesso em: 01 dez. 2015.

BRZEZINSKI, Iria. Formação de profissionais da Educação e mudanças da LDB/1996: dilemas e desafios? Contradições ou compromissos? In: BRZEZINSKI, Iria (Org.). LDB/1996 contemporânea: contradições, tensões, compromissos. São Paulo: Cortez, 2014, p. 112-133.

CARVALHO, Ana Beatriz Gomes; PIMENTA, Sônia de Almeida. Políticas públicas de formação de professores da educação básica a Distância: o contexto do pró-licenciatura. Práxis Educacional, Vitória da Conquista-BA, v. 6, n. 10, p.101-123, 2010.

COSTA, Celso José da; PIMENTEL, Nara Maria. O sistema Universidade Aberta do Brasil na consolidação da oferta de cursos superiores no Brasil. Educação Temática Digital - ETD, Campinas, v. 10, n. 2, p.71-90, 2009. 
DOURADO, Luiz; SANTOS, Catarina de Almeida. A Educação a Distância no contexto atual e o PNE 2011-2020: avaliação e perspectivas In: DOURADO, Luiz. Plano Nacional de Educação (2011-2020): avaliação e perspectivas. $2^{a}$ ed. Goiânia: UFG; Belo Horizonte: Autêntica, p. 155-191, 2011.

FARIA, Denilda Caetano de. A EaD como política de expansão da educação superior: da implementação da EaD e a institucionalização da UAB na UFT. In: Anped Centro Oeste - Encontro de Pesquisa em Educação da Região Centro-Oeste, 12, GT 02. Anais... Goiânia: XII ANPED Centro Oeste, 2014.

LEAL, Willany Palhares. Tecnologias e educação a distância nas políticas públicas de formação de professores: o habitus professoral na UNITINS. 2013, 255 f. Tese (Doutorado em Sociologia) - Universidade de Brasília, Brasília, 2013. Disponível em: <http://repositorio. unb.br/handle/10482/15371>. Acesso: em 13 dez. 2015.

MANCEBO, Deise; VALE, Andréa Araújo do; MARTINS, Tânia Barbosa. Políticas de expansão da educação superior no Brasil (1995-2010). Revista Brasileira e Educação, Rio de Janeiro, v. 20. n. 60, p. 31-50, jan./mar. 2015.

NASS, Daniel Perdigão. Licenciatura a distância em Física e Química no Tocantins: trajetórias, possibilidades e limites. 2012. 254 p. Tese (Doutorado em Ensino de Ciências) - Universidade de São Paulo, São Paulo, 2012.

UNIREDE. Histórico. Portal UniRede. Disponível em: < http://aunirede.org. br/portal>. Acesso em: 20 fev. 2016.

UNIVERSIDADE FEDERAL DO TOCANTINS. Projeto Pedagógico do curso de Licenciatura em Matemática (Modalidade EAD). Palmas: UFT, 2013.

UNIVERSIDADE FEDERAL DO TOCANTINS. Projeto Pedagógico do curso de Licenciatura em Química (Modalidade EAD). Palmas: UFT, 2009.

UNIVERSIDADE FEDERAL DO TOCANTINS. Projeto Pedagógico Institucional - PPI. Palmas: UFT, 2007. 
UNIVERSIDADE FEDERAL DO TOCANTINS. Resolução n. 06/2005, de 13 de outubro de 2005. Cria, em caráter experimental, o Curso de Licenciatura Plena em Biologia, Modalidade EaD. Palmas, 2005.

DENILDA CAETANO DE FARIA é doutoranda em Educação pela Pontifícia Universidade Católica de Goiás- PUC-GO. Realiza pesquisa na linha de pesquisa, Educação, Sociedade e Cultura, financiada pela Coordenação de Aperfeiçoamento de Pessoal de Nível Superior - CAPES. Servidora da Universidade Federal do Tocantins. Atua como administradora e professora de cursos EaD. E-mail: denilda@uft.edu.br

MOISÉS GREGÓRIO DA SILVA é doutorando em Educação pela Pontifícia Universidade Católica de Goiás (PUC-GO). Realiza pesquisa na linha de pesquisa, Educação, Sociedade e Cultura, financiada pela Fundação de Amparo à Pesquisa do Estado de Goiás - FAPEG. Professor do Instituto Federal de Educação, Ciência e Tecnologia de Goiás (IFG). E-mail: moisesgregorio2@gmail.com

MARIA ZENEIDE CARNEIRO MAGALHÃES DE ALMEIDA é doutora em História UnB (2009). Professora Adjunta PUC Goiás- EFPH e do Programa de Mestrado e Doutorado em Educação, Linha de Pesquisa Educação, Sociedade e Cultura. Coordenadora do NEPHEM/PUCGO do Grupo de Estudos e Pesquisas História, Sociedade e Educação no Brasil (HISTEDBR/UNICAMP/FE). Líder do Diretório (CNPq/PROPE) do Grupo de Pesquisa: "Educação, História, Memória e Cultura em diferentes espaços sociais" (PROPE/PPGE/PUCGO). E-mail: zeneide.cma@gmail.com 